\title{
Perancangan Sistem Pemilihan Cabang Olahraga di Dispora Kota Medan Berbasis Website
}

\author{
Designing a Sports Branch Selection System at Dispora Medan City Based on Website
}

\author{
Desy Ramadhani ${ }^{*}$, Dinda Zukhoiriyah ${ }^{2}$, Muthia Ramadhani ${ }^{3}$ \\ ${ }^{1,2,3}$ Ilmu Komputer, Universitas Islam Negeri Sumatera Utara \\ E-mail: 1desyramadhani1219@gmail.com, 2dindazukhoiriyah454@gmail.com, \\ 3zakiamuthia12@gmail.com
}

\begin{abstract}
Abstrak
Dengan teknologi komputer pemberian layanan dalam berbagai bidang menjadi lebih baik, cepat, tepat, akurat dan efisien. Dalam hal ini teknologi komputer jadi sarana wajib yang digunakan dalam kegiatan sehari-hari sehingga kini teknologi komputer digunakan di berbagai sekolah, perusahaan, instansi, termasuk di Dinas Pemuda dan Olahraga Kota Medan. Sistem tersebut berupa aplikasi berbasis web yang berisikan kriteria-kriteria untuk dapat menentukan cabang olahraga yang sesuai dengan keterampilan dan bakat yang dimiliki oleh siswa yang melakukan serangkaian tes untuk pemanduan bakat tersebut. Pemilihan cabang olahraga di Dinas Pemuda dan Olahraga Kota Medan berbasis web ini dibuat dengan bahasa pemrograman PHP dan menggunakan konsep prosedural, menggunakan database manajemen sistem MySQL, dan tools untuk DBMS nya menggunakan software XAMPP. PHP adalah bahasa skrip yang dapat ditanamkan atau disisipkan ke dalam HTML. PHP banyak dipakai untuk memrogram situs web dinamis. PHP dapat digunakan untuk membangun sebuah CMS. MySQL adalah Relation Database Management System (RDBMS) yang di distribusikan secara gratis dibawah lisensi GPL (General Public License). Dimana setiap orang bebas untuk menggunakan MySQL, namun tidak boleh dijadikan produk turunan yang bersifat komersial. Aplikasi pemilihan cabang olahraga ini dapat di akses oleh admin yang memiliki hak akses penuh pada aplikasi dan dapat di akses langsung oleh calon atlet atau olahragawan.
\end{abstract}

Kata Kunci : Perancangan Sistem, Dispora, PHP, MySQL, Aplikasi

\begin{abstract}
With computer technology, service delivery in various fields has become better, faster, more precise, accurate and efficient. In this case, computer technology has become a mandatory tool used in daily activities so that computer technology is now used in various schools, companies, agencies, including the Medan City Youth and Sports Office. The system is in the form of a web-based application that contains the criteria to be able to determine the sport according to the skills and talents possessed by students who carry out a series of tests for scouting these talents. This web-based selection of sports at the Medan City Youth and Sports Office was made using the PHP programming language and using procedural concepts, using the MySQL database management system, and tools for the DBMS using XAMPP software. PHP is a scripting language that can be embedded or embedded into HTML. PHP is widely used to program dynamic websites. PHP can be used to build a CMS. MySQL is a Relation Database Management System (RDBMS) which is distributed free of charge under the GPL (General Public License). Where everyone is free to use MySQL, but it should not be used as a commercial derivative product. This sports selection application can be accessed by admins who have full access rights to the application and can be accessed directly by prospective athletes or athlete.
\end{abstract}

Keywords: System Design, Dispora, PHP, MySQL, Application 


\section{PENDAHULUAN}

Sejarah singkat berdirinya Dinas Pemuda dan Olahraga Kota Medan sejak tahun 2003, pada tahun 2018 Dispora Kota Medan beralih ke tipe A. Dalam rangka upaya pembinaan dan pengembangan Pemuda dan Olahraga yang merupakan faktor potensial di dalam usaha pembangunan Kota Medan secara menyeluruh dan merata, maka dibentuklah Dinas Pemuda dan Olahraga Kota Medan yang terletak di Jalan Ibus Raya No. 129 B Medan. Dispora Kota Medan telah mengalami pergantian Kepala Dinas sebanyak 9 (sembilan) kali [1].

Dalam hal ini teknologi komputer jadi sarana wajib yang digunakan dalam kegiatan seharihari sehingga kini teknologi komputer digunakan di berbagai sekolah, perusahaan, instansi , termasuk di Dinas Pemuda Dan Olahraga Kota Medan. Dalam merealisasikan upaya sebagaimana dimaksud di atas, diperlukan suatu sistem pemanduan bakat yang dapat menunjang proses penentuan bakat cabang olahraga dengan efisien, sehingga mampu mencapai tingkat prestasi yang setinggi-tingginya.

Sistem tersebut berupa aplikasi berbasis web yang berisikan kriteria-kriteria untuk dapat menentukan cabang olahraga yang sesuai dengan keterampilan dan bakat yang dimiliki oleh siswa yang melakukan serangkaian tes untuk pemanduan bakat tersebut. Sehingga hasil yang dihasilkan lebih akurat dan baku, dengan demikian akan memberikan kesempatan kepada atlet muda berbakat pada cabang-cabang olahraga yang diminati yang berprestasi secara optimal sesuai dengan keterampilan dan bakat masing-masing, sehingga akan meningkatkan kualitas para atlet muda.

Penelitian yang terkait dengan perancangan sistem pemilihan cabang olahraga di Dispora Kota Medan berbasis website yang telah dilakukan beberapa peneliti terdahulu yang menghasilkan aplikasi sistem pendukung keputusan pemilihan yang dimana peneliti sebelumnya menggunakan metode profile matching[2]. Dari penelitian jurnal ini dibutuhkan sistem aplikasi pemilihan cabang olahraga di Dispora Kota Medan berbasis Website. Aplikasi ini diharapkan mampu memberikan kemudahan pada pihak Dispora untuk memilih atlet.

Kebutuhan Sistem mengembangkan sebuah sistem atau bisa diartikan bahwa kebutuhan sistem adalah pernyataan tentang apa yang harus dilakukan oleh sistem dan pernyataan tentang karakteristik yang harus dimiliki sistem merupakan tujuan dari kebutuhan sistem. Kebutuhan perancangan Perancangan Pemilihan Cabang Olahraga di Dispora Kota Medan.

1. Hardware dapat bekerja berdasarkan perintah yang telah ditentukan ada padanya, atau yang juga disebut dengan istilah instruction set. Dengan adanya perintah yang dapat dimengerti oleh hardware tersebut. Komponen hardware yang digunakan Monitor, Keyboard, Mouse, Random Access Memory (RAM), processor.

2. Software sistem operasi yang kompleks yang mempunyai banyak fungsi. Fungsi yang pertama adalah untuk mengatur semua perangkat keras komputer yang terhubung dengan CPU. Fungsi kedua yaitu menerjamahkan segala aktivitas pemakai kepada CPU agar segala yang diperintahkan oleh pemakai dapat dikerjakan oleh CPU[3].

3. Hosting adalah sebuah penyedia layanan internet untuk penempatan informasi-informasi baik untuk halaman-halaman web, penyimpanan email, database, dsb.

4. Domain adalah nama atau alamat unik sebuah website, biasanya diakhiri dengan .com, net, .biz, .org, .info, .tv, dsb[4]. 
XAMPP adalah perangkat lunak komputer yang sistem penamaannya diambil dari akronim kata Apache, MySQL atau MariaBD, PHP, dan Perl. Program aplikasi XAMPP berfungsi sebagai server lokal untuk mengampu berbagai jenis data website yang sedang dalam proses pengembangan. XAMPP bisa digunakan untuk menguji kinerja fitur ataupun menampilkan konten yang ada didalam website kepada orang lain tanpa harus terkoneksi dengan internet, atau istilahnya website offline[5]. Visual Studio code adalah sebuah teks editor ringan dan handal yang dibuat oleh microsoft untuk sistem operasi multiplatform, banyak fitur-fitur yang disediakan oleh Visual Studio Code diantaranya Intellisense, Git Integration, Debugging, dan fitur ekstensi yang menambah kemampuan teks editor[6].

a. PHP sendiri sebenarnya merupakan singkatan dari "Hypertext Preprocessor", yang merupakan sebuah bahasa scripting tingkat tinggi yang dipasang pada dokumen HTML. Sebagian besar sintaks dalam PHP mirip dengan bahas C, Java dan Perl, namun pada PHP ada beberapa fungsi yang lebih spesifik[7].

b. Cascading Style Sheet (CSS) adalah kumpulan kode program yang digunakan untuk mendesain atau mempercantik tampilan halaman HTML. Dengan CSS dapat mengubah desain dari text, warna, gambar dan latar belakang dari hampir semua kode tag HTML[8].

c. MySQL adalah salah satu Database Management System (DBMS) dari sekian banyak DBMS seperti oracle, MS SQL, Postagre SQL, dan lainnya. MySQL berfungsi untuk mengolah database menggunakan bahasa SQL. MySQL bersifat open source sehingga dapat digunakan secara gratis[9].

jQuery merupakan library yang menggunakan interface javascript yang dapat menyederhanakan penelusuran dokumen, penanganan kejadian (event), animasi, dan interaksi dengan AJAX. Pada awal pengembangannya, jQuery ditujukan untuk kebutuhan web desktop, tetapi seiring dengan berkembangnya web mobile maka dibuat atau disesuaikan untuk kebutuhan web mobile lewat jQuery Mobile[10].

\section{METODE PENELITIAN}

Metode pengumpulan data yang digunakan dalam penelitian ini adalah sebagai berikut:

a. Metode observasi, pengamatan yang dilakukan secara sistematis untuk kemudian dilakukan pencatatan dengan menggunakan dan mempelajari praktek-praktek pelaksanaan ditempat penelitian meliputi proses penyampaian informasi Dispora Kota Medan serta proses promosi kegiatan olahraga yang ada di Dispora Kota Medan

b. Metode kepustakaan, untuk memperluas cakrawala pandang, maka perlu membaca buku yang sesuai dengan permasalahan yang ada, sebagai bahan pertimbangan untuk mendapatkan yang mengacu pada buku, jurnal, catatan yang dapat menunjang penyusunan penelitian tentang website Dispora Kota Medan.

c. Metode wawancara, untuk mendapatkan masukan berkenaan dengan sistem yang dibuat maka dilakukan wawancara yang berkaitan dengan permasalahan yang terjadi dalam pemilihan cabang olahraga di Dispora Kota Medan.

\subsection{Perancangan Use Case Diagram}

Use case diagram menunjukkan fungsi suatu sistem atau kelas dan bagaimana sistem tersebut berinteraksi. Use case diagram dapat digunakan selama proses analisa untuk menangkap requirement sistem dan untuk memahami sistem bekerja. Selama tahap desain use case diagram berperan untuk menetapkan perilaku (behaviour) sistem saat diimplementasikan. Dan berikut adalah use case diagram sistem pemilihan cabang olahraga siswa. 


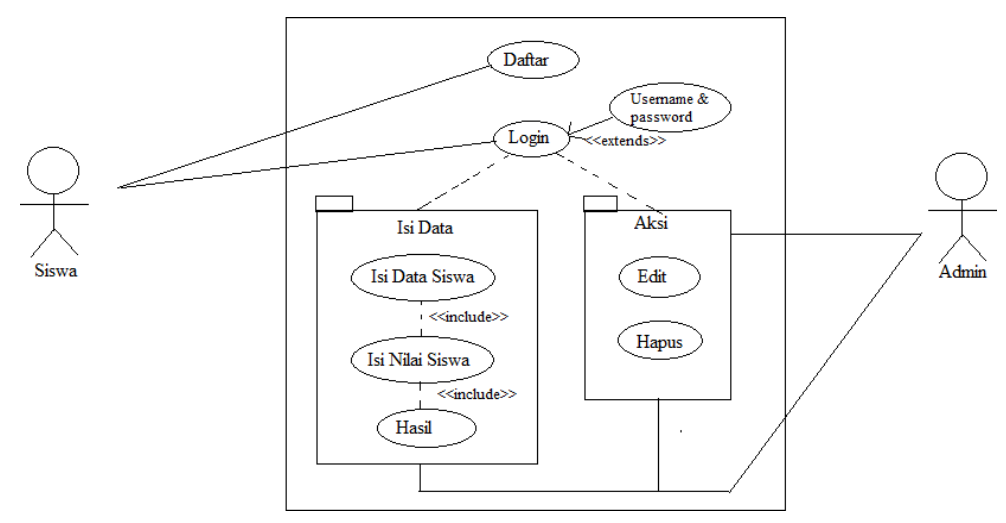

Gambar 2.1 Use Case Diagram

Gambar 2.1 menjelaskan use case aplikasi yang dibangun. Terdapat 2 aktor yaitu admin dan user. Didalam aplikasi ini admin termasuk tim penyeleksi dari staff pegawai Dinas Pemuda dan Olahraga, sedangkan user termasuk siswa atau olahragawan yang mengikuti seleksi pemanduan bakat. Adapun admin dapat melakukan login, mengisi data alternatif, nilai alternatif dan melihat hasil serta melakukan aksi edit dan hapus pada tiap-tiap tahap penyeleksian, sedangkan user dapat melakukan daftar, kemudian dilanjutkan dengan login dan mengisi data alternatif pribadi, nilai alternatif dan melihat hasil tanpa seleksi tanpa bisa melakukan aksi edit dan hapus.

\subsection{Perancangan Activity Diagram}

Activity diagram tidak menggambarkan proses-proses dan jalur-jalur aktivitas dari level atas secara umum. Sebuah aktivitas dapat direalisasikan oleh satu uses case menggambarkan bagaimana aktor menggunakan sistem untuk melakukan aktivitas.

Berikut adalah activity diagram untuk menjelaskan bagaimana sisi user (siswa), admin dan sistem bekerja berdasarkan perannya masing-masing.

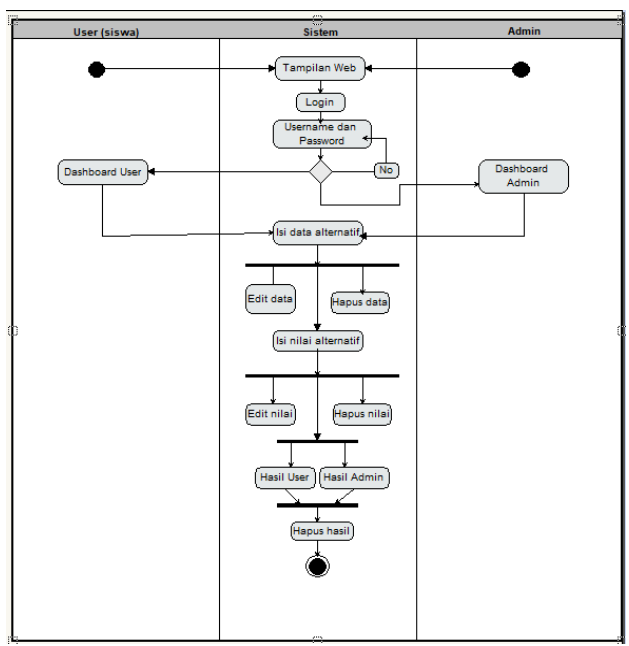

Gambar 2.2 Activity diagram

Gambar 2.2 menjelaskan activity diagram aplikasi sistem pemilihan cabang olahraga siswa. Proses awal adalah user dan admin mengakses website yang kemudian akan ditampilkan oleh sistem. Kemudian proses selanjutnya yang dapat dilakukan oleh user (siswa) dan admin melakukan login, isi data alternatif, lalu dapat melakukan aksi yaitu edit dan hapus.

Selanjutnya melakukan pengisian nilai alternatif siswa, dan kemudian halaman hasil yang ditampilkan oleh sistem antara sesi user (siswa) dan admin adalah halaman yang berbeda. Yaitu 
user (siswa) hanya dapat melihat data dan hasil atas nama pribadi, sedangkan admin dapat melihat data seluruh user (siswa).

\section{HASIL DAN PEMBAHASAN}

Pemilihan cabang olahraga di Dinas Pemuda dan Olahraga Kota Medan berbasis web ini dibuat dengan bahasa pemrograman PHP dan menggunakan konsep prosedural, menggunakan database manajemen sistem MySQL, dan tools untuk DBMS nya menggunakan software XAMPP.

Sedangkan pada tampilan, penulis menggunakan jQuery, CSS, Framework Bootstrap yang dikembangkan oleh tim pengembang Twitter yang sudah mendukung fasilitas-fasilitas pada website modem seperti tampilan yang responsive untuk tampilan mobile.

Aplikasi pemilihan cabang olahraga ini dapat di akses oleh admin yang memiliki hak akses penuh pada aplikasi dan dapat di akses langsung oleh calon atlet atau olahragawan. Aplikasi pemilihan cabang olahraga ini dapat diakses secara online, oleh karena itu aplikasi ini menggunakan domain dan hosting agar dapat di akses oleh siapa pun dan dimana pun selama user mempunyai koneksi internet dan izin akses masuk ke aplikasi tersebut.

Implementasi aplikasi pemilihan cabang olahraga siswa ini memiliki beberapa fitur, diantaranya yaitu: menu daftar, login, beranda, menu data alternatif, menu nilai alternatif, menu hasil SPK, dan logout.

\subsection{Menu Daftar}

Menu daftar dari aplikasi ini adalah form untuk melakukan registrasi keanggotaan siswa, itu artinya hanya siswa yang melakukan tes identifikasi bakat untuk menentukan cabang olahraga siswa tersebut yang bisa melakukan registrasi dan mengisi form.

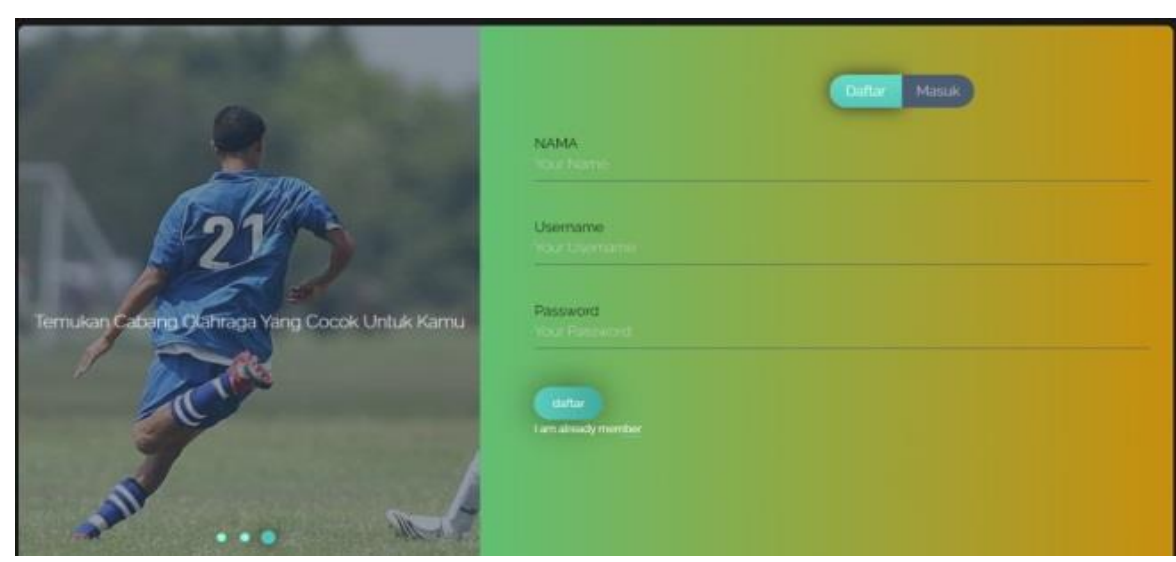

Gambar 3.1 Tampilan Menu Daftar

Pada menu daftar terdapat form untuk mengisi nama, username, password untuk registrasi keanggotaan siswa, dengan demikian hanya siswa yang dapat mengisi form ini, sedangkan untuk admin tidak perlu melakukan pendaftaran.

\subsection{Menu Login}

Menu login dari aplikasi ini adalah tampilan ketika aplikasi dijalankan dan merupakan form untuk dapat masuk atau mengakses aplikasi sepenuhnya. 


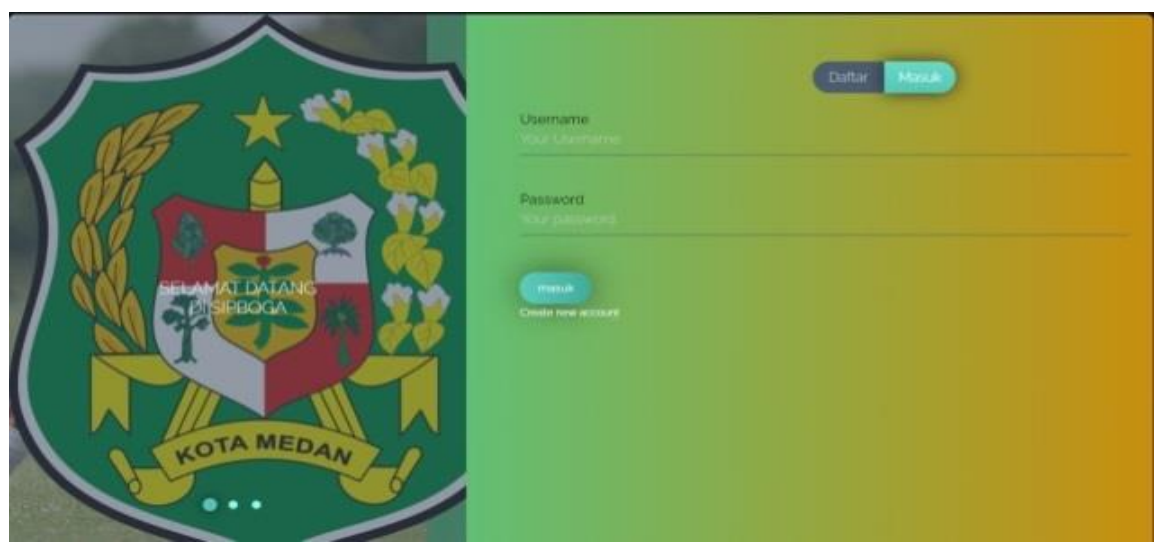

Gambar 3.2 Tampilan menu login

Pada menu login terdapat form untuk mengisi username dan password, dengan demikian user atau siswa yang sudah melakukan pendaftaran bisa mengisi menu login untuk dapat masuk ke sistem aplikasi ini. Dan jika username dan password yang di isi berisi informasi atau data yang salah, maka akses akan ditolak.

\subsection{Halaman Beranda}

Pada halaman ini, tampilan untuk sesi user dan admin adalah sama, yang menjadi pembeda adalah username saat login, seperti gambar berikut.

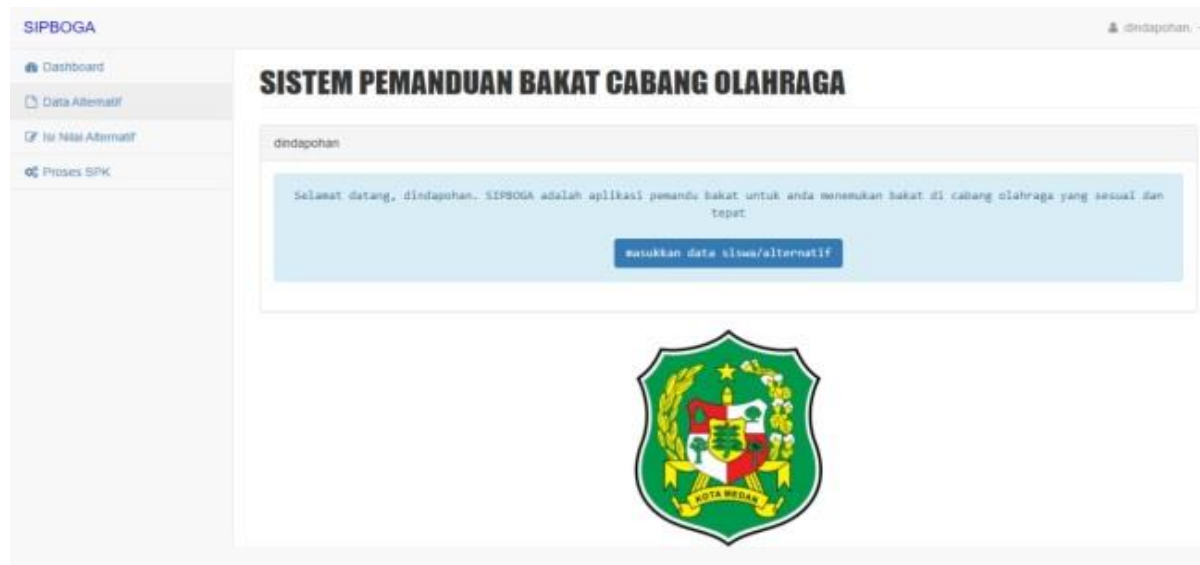

Gambar 3.3 Halaman Beranda

3.4 Menu Data Alternatif

Pada menu ini, data yang akan ditampilkan antara sesi user dan admin adalah berbeda. 
a. User

Pada sesi user, data yang ditampilkan hanya data user tersebut saja.

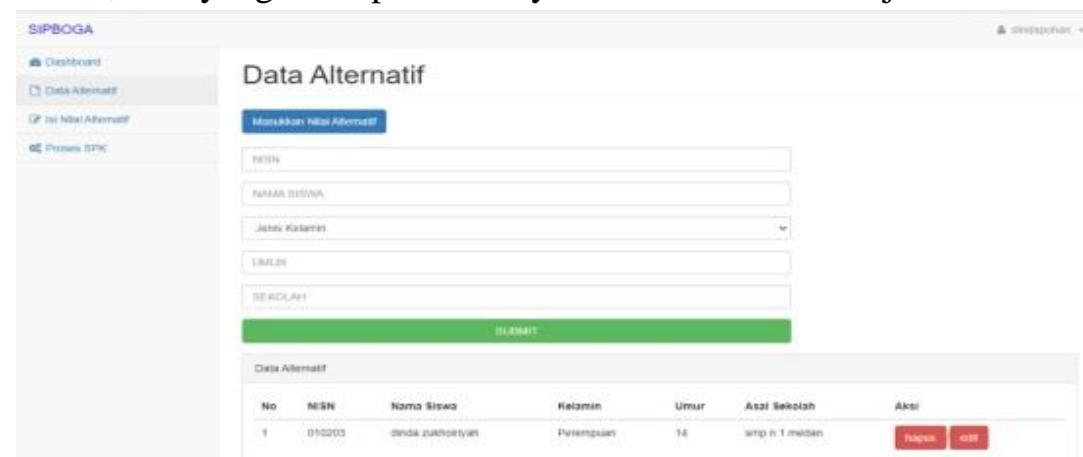

b. Admin

\section{Gambar 3.4 Menu data alternatif (siswa)}

Pada sesi admin, seorang admin bisa melihat data-data siswa yang sudah mengisi data untuk tes pemilihan cabang olahraga. Dengan demikian admin memiliki akses penuh dalam aplikasi dan data siswa.

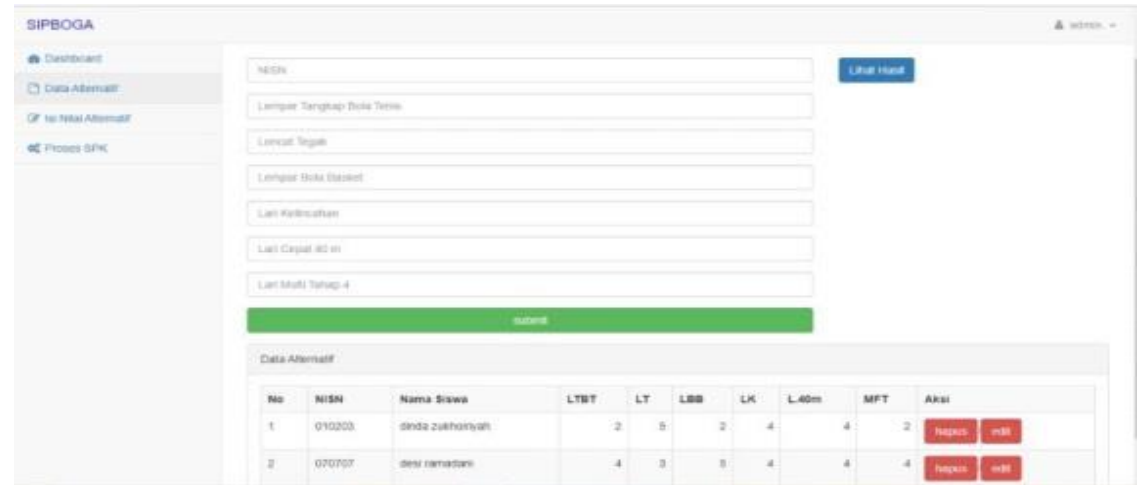

\section{Gambar 3.5 Menu data alternatif sesi admin}

\subsection{Menu Nilai Alternatif}

Pada menu ini, data yang ditampilkan berbeda antara user dan admin.

a. User

Setelah user memasukkan data alternatif, kemudian dilanjutkan dengan memasukkan data nilai yang sudah di dapat dari tes identifikasi bakat secara langsung, sesuai dengan kriteria-kriteria yang tertera pada aplikasi. Data-data yang ditampilkan hanya data user tersebut saja.

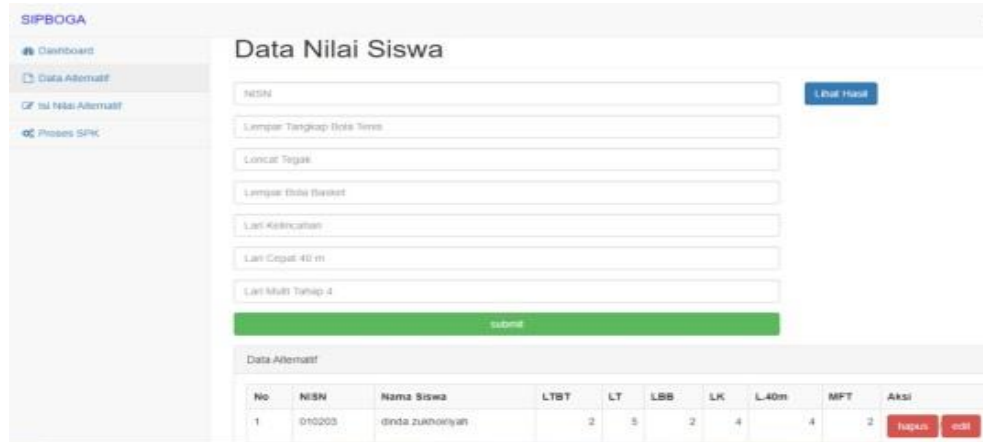

Gambar 3.6 Menu nilai alternatif user (siswa) 


\section{b. Admin}

Admin dapat mewakilkan siswa secara langsung mengisi kan nilai siswa yang melakukan tes, dan kemudian bisa melihat semua data siswa yang sudah melakukan tes dan menggunakan sistem aplikasi ini.

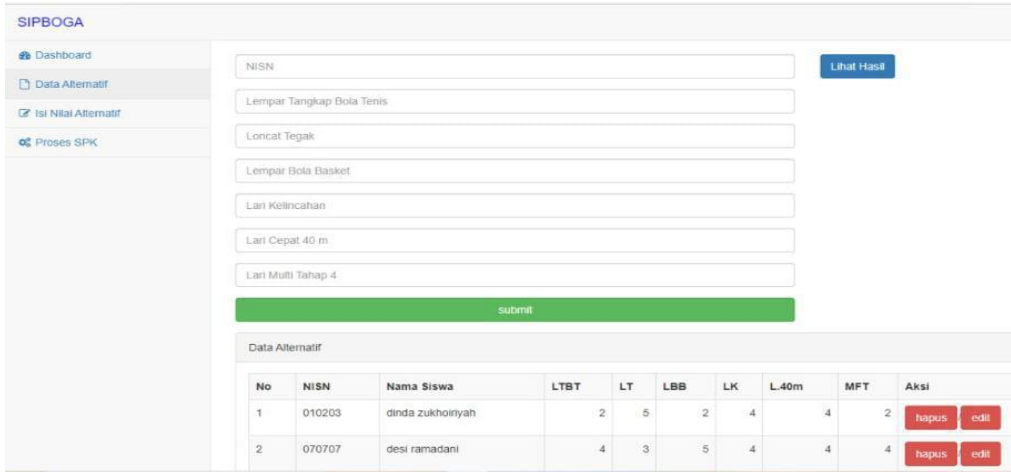

Gambar 3.7 Menu nilai alternatif sesi admin

\subsection{Menu Hasil}

Pada menu ini, user dan admin memiliki hak akses yang berbeda yaitu, dari segi data yang ditampilkan.

a. User

User hanya dapat melihat hasil dari tes nya sendiri pada menu hasil ini setelah memasukkan semua data yang diminta pada aplikasi.

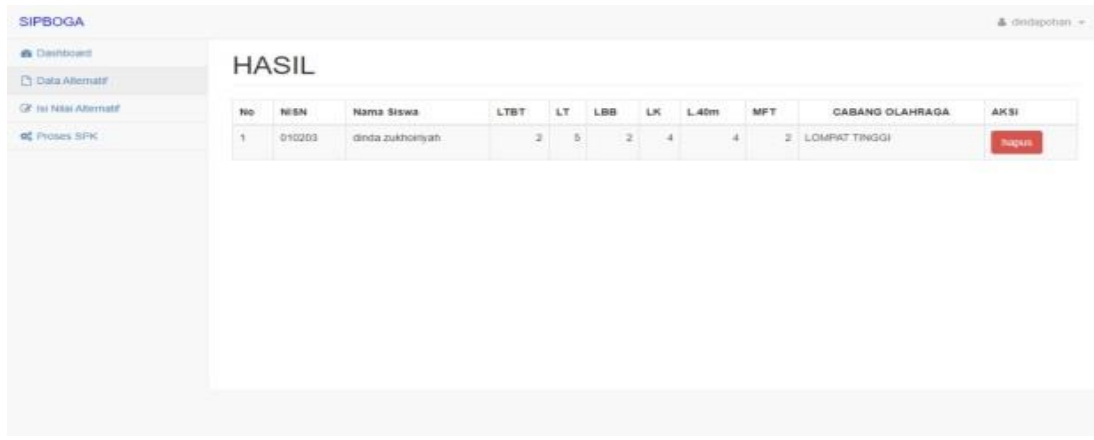

\section{Gambar 3.8 Menu hasil sesi user (siswa)}

b. Admin

Admin dapat melihat data-data (siswa) yang sudah melakukan tes.

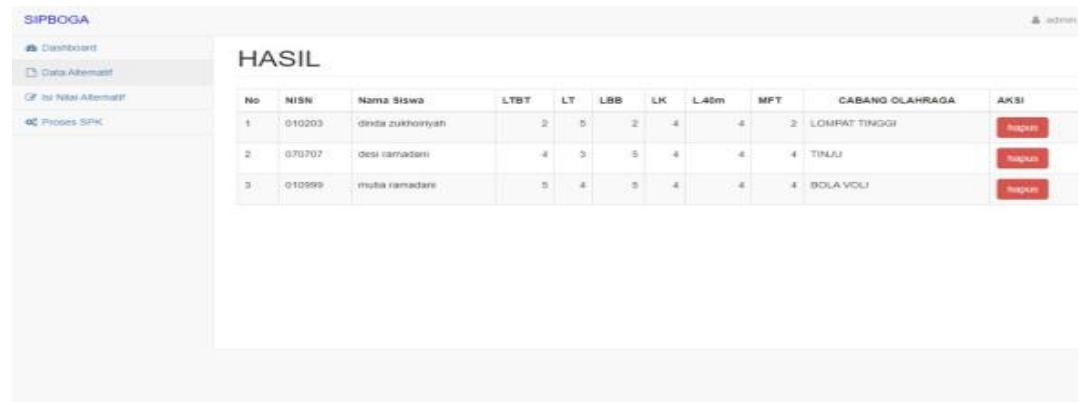

Gambar 3.9 Menu hasil sesi admin 


\section{KESIMPULAN DAN SARAN}

Penerapan Aplikasi Pemilihan Cabang Olahraga di Dispora Kota Medan akan mempermudah penentuan cabang olahraga yang tepat bagi atlet serta dapat membantu tim penyeleksi untuk mendapatkan keputusan yang lebih cepat dan akurat sehingga dapat menghasilkan sebuah kinerja yang efektif guna membantu pegawai Dispora Kota Medan. Dengan adanya aplikasi ini dapat meminimalisirkan biaya kertas dan waktu yang diminta dan dapat mengantisipasi keamanan data atlet yang telah disimpan.

Pada penelitian selanjutnya diharapkan aplikasi ini dapat dikembangkan dengan membuat desain responsif sehingga aplikasi dapat beradaptasi di berbagai platform seperti tablet, telepon pintar, dll. Meningkatkan keamanan sistem sehingga tidak ada yang disalahgunakan. Serta harus adanya maintenance terhadap sistem tersebut agar efektivitas sistem dapat terus berjalan dengan baik dan optimal.

\section{DAFTAR PUSTAKA}

[1] Sejarah Dispora Kota Medan. Diakses 12 November 2021. https://pemkomedan.go.id/

[2] Youlan Indira Putri. 2019. Rancang Bangun Sistem Pendukung Keputusan Pemilihan Pemain Futsal Berbasis Web menggunakan Metode Profile Matching. 12(2) : 85.

[3] Elisabet, Y.T. Rita, I. 2017. Pengantar sistem informasi. Yogyakarta:Andi.

[4] Ali, Z. 2011. Cepat \& Mudah Membuat:Website Keren Dengan Worpress 3.X. Jakarta: Mediakita.

[5] Muhammad, Y.H.S. Dinda, A.P. 2020. Membuat Sistem Informasi Gadai Online Menggunakan Codeigniter Serta Kelola Proses Pemberitahuannya. Bandung: Kreatif Industri Nusantara.

[6] A.Yudi Permana. 2019. Perancangan Sistem Informasi penjualan Perumahan Menggunakan Metode SDLC Pada PT.Mandiri Land Prosperous Berbasis Mobile. Jurnal Informatika. 10(2) : 155.

[7] Didik, S. 2017. Buku Sakti Pemrograman Web. Yogyakarta: Start Up.

[8] Iwan, P. Ronal, W. 2018. Sistem Informasi Kursus PHP Dan MYSQL. Sidoarjo: Uwais Inspirasi Indonesia.

[9] Anhar. 2010. PHP \& MySQL Secara Otodidak. Jakarta: Mediakita.

[10] Ir. Yuniar Supardi. 2018. Membuat Program Smartphone untuk Android,Blackberry,dan iOS. Jakarta: PT Elex Media Komputindo. 